\title{
HR MANAGERS AND ENVIRONMENTAL SUSTAINABILITY: STRATEGIC LEADERS OR PASSIVE OBSERVERS?
}

\author{
Dr Candice Harris (1) and Dr Helen Tregidga (2)
}

(1) Senior Lecturer in Management, AUT University, Private Bag 92006, Auckland 1142 NEW ZEALAND candice.harris@aut.ac.nz

(2) Senior Lecturer in Accounting, AUT Universty, Private Bag 92006, Auckland 1142

NEW ZEALAND helen.tregidga@aut.ac.nz

Submission to Track 1: Management, Work and Organisation

\section{INTRODUCTION}

While many organisations have been quick to jump onboard the 'sustainability bandwagon' little appears to have been done to consider the role of, and effect on, the HR function and manager. In fact, organisations have tended to treat sustainability and HR in silo. This paper examines questions such as: How are HR managers defining and enacting corporate sustainability? And what is the effect of the HR managers' social and political contexts in this role? We do $s o$ by focusing on the relationships between HR and environmental sustainability. In particular, we explore the challenges posed to, and reactions of, HR and HR managers by the concept of sustainable development and the corporate sustainability rhetoric.

Drawing on a set of interviews undertaken with 11 New Zealand (NZ) HR managers we explore three related aspects of morality identified by Fineman (1997): private, conventional and enacted. We analyse a group of HR managers' private views on the environment and consider how these relate to their organisations stated postion, as well as how they are enacted (or not) within their work context. In doing so, we begin to examine how green territories are construed and contested within the HR arena, something not consdered in the extant literature. Moreover, we explore and analyse the current state of HR and environmental sustainability, examining not only what the HR function is doing in the name of sustainability, but also, what they believe they can and should be doing. We therefore begin to critically examine the relationship between HR and environmental sustainability and start to explore what sustainability may mean for various HR functions.

We structure the paper as follows. First, we review the background literature. Here we consider the sustainable development concept within the business context and the emerging HR literature in the area. Second, we present our framework and approach taken in the paper followed by an overview of our data sources and method. Findings are then presented and discussed. The paper ends with conclusions and implications.

\section{BACKGROUND LITERATURE}

The natural environment has become a site of discursive struggle arising out of alternative representations of the human-nature relationship (and subsequently the organisation-nature relationship) and contestation around what the 'correct' relationship should be (e.g. see Dryzek 1997). A range of different discourses on the environment exists in this struggle. Sustainable development discourse is one such discourse.

It is widely understood that the 'meaning' of sustainable development is contested (Dryzek 1997; Gladwin et al. 1995; Jacobs 1999; Sachs 1999; Welford 1997). To recognize this multiplicity and range of meanings, much of the sustainability literature refers to the 'weak' 
vs. 'strong' sustainability continuum (Dobson 1998; Wackernagel and Rees 1996). These opposing ends of a continuum are founded on the triple bottom line' perspective of sustainable development (Elkington 1997). The 'triple bottom line' suggests sustainability is made up of three elements; economic, environment and society. How the three elements are conceived, and the interaction between them conceptualised, leads to the weak/strong divide. It is the balance of trade-offs that define the difference between the conceptualizations.

Under weak sustainability the three elements are viewed as related, but fundamentally separate entities. Trade-offs are therefore made where the advancing of one component will occur at the expense of others. It is upon these foundations that the business case for sustainability is made. The business case suggests that the economy is equal to the environment and society, and therefore, sustainability becomes about achieving win-wins; actions which are both good for the environment and the busness (e.g. recycling, reduction of waste, and other e $\infty$-efficiencies). However, this often leads to the economy being prioritized over the environmental and social. Under strong sustainability the three elements are conceptualized in a different way. Here the economy, society and environment are not separate entities, the economy is perceived as part of, not apart from, society and the environment and the recognition is made that the economy relieson these two elements not only for its 'success' but also for its existenœ. The 'strong' perspective ultimately places emphasis on the environment and society and fundamentally acknowledgesthe presence of limits. In this paper, we focus on environmental sustainability. We do so to highlight the environmental element of sustainability which we consider important, and importantly overlooked, within the current HR arena.

Since Shrivastava's (1994) call for organisation studies to seriousy engage in environmental discourse, there has been a notable increase in organisation and management studies consideration of the natural environment. The recognition of the environmentally destructive nature of organisations' activities (Welford 1997) and acknowledgement that organisations have contributed to the present ecological 'crisis' is likely to be one reason for this consideration. So too, is the recognition that the business community is essential to any movement towards sustainability (Hawken 1993). However, whilst organisation studies and disciplines such as accounting (see for example Gray and Bebbington 2001; Unerman et al. 2007) and operations management (see for example Sarkis 2006) have been active in considering their role on, and impact of, environmental sustainability, the HR field has thus far largely failed to engage.

A recent report by the WBCSD (2005) considers the relationship between HR and sustainable development. They note the importance of HR in sustainability and note how sustainable development can be considered in a number of core HR functions (e.g. recruiting and retaining top talent, creating incentives for exceptional performance, and enhancing critical competencies). Another industry group CIPD has also begun exploring the role of HR in organisational 'greening' (see Davies \& Smith 2007; Glade 2008). Academic literature is, at present, lacking.

It is acknowledged that sustainability will not be 'busness as usual' (Bebbington and Gray 2001). While some suggest that a 'revamp' of existing models and theories of organisations is a way to bring about sustainability (for example see Hart 1995; Starik and Rands 1995), others note that more radical change is required (Gladwin et al. 1995; Purser et al. 1995). Recent analyses of the corporate sustainability discourse notes that while organisations may be 'talking green' the level to which they may be 'acting green' is questionable (Milne et al. 2006; 2008; Prasad and Elmes 2005). We believe that any corporate shift from a 'business as usual' position to a more environmentally respons ble paradigm requires company-wide environmental sensibilities. We therefore, in this paper, examine both the effect that the sustainability concept has had on the HR function and manager as well as the role of HR in 
enabling and fostering environmental sustainability. We do so by drawing on the framework and approach utilized by Fineman (1997). In the following section we outline thisframework.

\section{FRAMEWORK AND APPROACH}

We take a social constructionist approach and seek to elucidate the personal and social meanings of environmental sustainability as situated in HR managers' everyday working realities. In his study of 'green' managers in the UK automotive industry, Fineman (1997) examines the social and political contexts of managers' organisational lives and how they interact with, and define, the green corporate agenda. Fineman (1997) addresses the question 'can the moral imperative and ethical valuesunderpinning the wider environmental debate be enacted by managers?' by exploring three related sub-questions. We outline these sub-questions below in relation to how they are understood and utilized in our study which explores the moral imperative and ethical values of a group of NZ HR managers and addresses whether they can be enacted within their everyday work contexts. The three related questions adopted from Fineman (1997 p. 32) are:

1. What are the HR managers' private moral positions on the environment?

Here we are concerned with an individual's personal views on the environment, including internalized views on what is 'right' or 'wrong'. Such views are often reflect parental, educational, community and religious influences (Fineman, 1997)

2. How do such beliefs transfer to managers' views about what is appropriate for their work roles, and how are they reconciled with the conventional morality of the corporation its public statements of environmental intent?

The HR managers' awareness of the organisation's stated position on the environment and sustainability, either internal or externally espoused, is considered here. Awareness of conventional morality, reflected through such things as corporate symbols, policies, codes of conduct and public reports and other statements, is important when considering everyday working realities. Job roles are contextualized and have 'norms' or 'ought's' which need to be reconciled with personal postions and values.

3. What e motions, rationalisations and political influence HR managers' enacted morality - what they do (or say they do) in terms of environmental protection and action?

Manifest actions - which may be different from what people say they ought to do - are explored. Moral rules in use, a product of context and situation-specific interests and needs are considered

In addition to these three questions we explored a fourth area:

4. What is, should, or can be the role of HR and the HR manager in fostering environmental sustainability within organisations?

We asked the HR managers to reflect on what they believed the NZ HR community is currently doing, can do, or should do.

Findings are discussed below after data sources and method are outlined.

\section{DATA SOURCES AND METHOD}

Thi s paper is based on findings from interviews with $11 \mathrm{HR}$ managers based in the Auckland and Wellington, NZ. The participants were sourced from the private, public and not-for-profit sectors, covering a range of organisations from banking, software development, hotel, manufacturing, tertiary education and social service industries. Four of the 11 organisations are multi-nationals. Participants were HR managers holding a senior position requiring them to make decisions or perform tasks that influence organisational practices and/or culture. Eight femalesand three males, with ethnic backgrounds ranging from NZ European, Maori, 
Pacific Isand and Asian, were interviewed. Interviews were conducted face-to face and lasted for up to an hour, during which participants were asked questions organised around the four themes identified above. Interviews were recorded and transcribed.

It is important to note and recognize here that as authors we do not ourselves share the same views or environmental perspective. While we both share an interest in, and concern for the environment, as evidenced by conducting research in this area, the level and extent of these views and perspectives are differing - with arguably one author being more 'radical' than the other. We believe these differing views and perspectives have added to the paper through the data analysis phase of the research.

\section{FINDINGS}

\section{Private 'Green' Positions}

Generally, participants discussed their internalized views of the state of the environment in an open and seemingly honest manner.

I' $m$ a believer in the concept of global warming and climate change. So, yes I subscribe to that argument.

I me an, my Dad, used to throw litter out the car and I used to be absolutely appalled... I just was personally affronted at that.

Protection of NZ's clean, green image was a common reference and it appeared that, along with parents, other relatives and former employers, living in NZ had an impact on participants' views and values.

So I think we've [NZ got an image of it [clean and green]... and compared to world standards we're not too bad but I don't think we're great.

So, I guess sustainability and manage ment of farmand is something that l've grown up with. So although l've done my far share of weed spraying with very very toxic things, yeah, Ive been brought up to care and manage the environment in a sustainable way.

Visible environmental impacts seemed to dominate their positions, for example factory smoke stacks, litter, and noticeably, packaging.

I do, I a m deeply offended at the way we are forced to buy some products that are heavily packaged with the polystyrene bases and the plastics and the cardboard packaging... you go grocery shopping and you co me home with stuff and you then actively, you think about taking everything out of all its packaging and it does offend me.

One of the things that really irks me is excess of packaging. I don't know how to avoid it except to choose not to buy that particular product.

While concern for the environment was expressed by all participants, many of the participants, like the comments above demonstrate, did not express many actions beyond recycling or picking up litter. As such there appeared a failure to consider some of the harder environmental questions such as purchasing and consumption decisions

Furthermore, at the same time, for many participants their concern was moderated by a cynicism about their ability to know about the environment and sustainability based on the 'noise' and 'hype' created in the media on such topics. 
My feeling is that there is a lot of, well, what I see, is a lot of media hype really about the environ ment. It is in a poor state, however, there's a lot of, a lot of confusion around, among the scientific world about how much influence we have on climate change generally.

I think, when you start, and I only know it through the media. So I think I get, you know, you get a very slanted view and they see what they want to.

Overall, concern for the environment in their private life ranged from mildly to somewhat interested and appeared comfortable with these positions. A realist or 'reasonable' self description was also evident, with several participants noting that they were 'not radical' or 'obsessive'.

\section{The Green Employer}

All participants were aware of their organisation's position on the environment.

Well, I'm pleased to say we do have a policy which you know, is always a great starting point. I wouldn't say it's sophisticated and advanced, but I think it has a level of understanding and maturity and has identified the environment in all its facets as an important issue.

If I were honest I wouldn't be able to recite it. But l'maware of initiatives such as the transport scheme and recycling...

However, most were not actively involved in the construction or redefining of the position, including one participant who was a member of their organisation's environmental council due to his top management position. Organisation's tended to communicate internally, and many did not have public statements on the environment:

It's a slightly kiwi thing about it. Just getting on with it but not blowing the tru mpet too loudly.

Actions taken in relation to the environment focused on paper use (e.g. double-sided printing), recycling of paper and rubbish and other eco-efficiencies.

So we've got, you know, recycling arrangements, we're energy conscious, you know, we're turning lights off, thinking about our heating systems, thinking about, you know, how we are managing all those kinds of issues.

And perhaps due to public statements being relatively limited in intention and extent, most did not feel that there was a gap between the organisation's public statements on the environment and sustainability and what the organisations were actually doing.

\section{Lim iting and Limited Action}

Participants were aware that their enacted morality was limited.

Well, you know, I think, it's all very well the paper, but papers like the least of our worries when you look at mobile phones, computer equipment, you know, old furniture, like the landfill that organisations must create is huge. So I think we've done the easy things, like turn off the lights. Recycle paper.

It was actually a marketing exercise more than anything, but what I guess l've done is tried to support them with it. For instance, when new staff come on board, like part of their induction, I will go through and talk to the $m$ about the new initiatives we have, show them the recycling stations or just talk to them generally about it. 
The business case was given as a strong rationalisation for this limited action and pursuing eco-efficiencies in their departments to save money for the organisation was seen as the goal. The business case was also cited as a reason for lack of action, as it was 'not a priority', especially in the current resource constrained economic environment.

And I would say that as an organisation, if it, it's like any organisation, if it works in their favour, so they look good in an environmental way and it helps save them money, then they'll do it... if it costs an organisation in the way they look, or in how much it's going to cost to sort it out, then it becomes an issue.

While they supported initiatives that were implemented by their organisation the HR managers were not a key driver of these, rationalised by the following arguments.

Argu ment 1. Environmental sustainability is 'not a priority' for HR.

Argument 2. HR do not have the resources to pursue environmental sustainability initiatives

Argu ment 3. HR have more urgent priorities related to people.

Argu ment 4. HR do not have time.

Ultimately, participants saw environmental initiatives as 'non priorities' or as 'nice to do's' and, as can therefore perhaps be expected, when resource stretched and balancing a range of 'priorities', such initiatives did not get considered.

Interestingly, no participants noted that they would not know how they would contribute to the environmental agenda. However, in our investigation of what the HR managers believed the HR function could or should be doing; we found a very limited, or perhaps just under considered, view.

\section{HR Transforming the Workplace}

All participants felt that the HR function has a role in fostering environmental practices within an organisation due to their role as stewards of values, and as skilled communicators in the organisation.

As part of HR we're responsible for driving culture. But it's interesting, our values have just come out. I can't reme mber. But I don't think environment sits in there.

We're dealing with people so much and all parts of the organization. I mean, it seems crazy for us not to be really involved in it.

However, participants did not see a role for HR as the strategic drivers of environmental and sustainability initiatives. Instead they saw themselves as the ideal partners to communicate the relevant values to encourage behaviour change, once strategy had been developed outside of HR. By having other stakeholders (e.g. senior managers, customers) responsible for driving for sustainability initiatives, participants felt it would gain more traction, than if driven by HR. Thus, there is a reluctance to champion sustainability from the HR platform in a pro active manner.

It's not something that HR would be the sole proprietor of. We prioritise things and you know, its, there's stuff that just has to be done and then the wish list is kind of at the botto $m$ and to be honest, we just battle to get to the nice-to-have stuff.

I know for us if our customers really put pressure on us that would change it. 
The problem is if it sits too thickly in HR no one else takes responsibility. So, you know, like sometimes they, like, you think, oh, HR, its mumbo jumbo, it doesn't actually matter, just ignore it, they'll go away. So I think sometimes it might be better if it does sit out in the business because they would take a bit more responsibility and a bit more energy in behind it.

\section{CONCLUSIONS AND IMPUCATIONS}

Findings indicate the HR managers espouse private moral positions around concern for the environment, however environmental action in their personal lives appears limited (mainly to recycling). While HR managers are aware of the conventional morality of the organisation, many do not appear to be actively involved in shaping the organisation's position. In regard to enacted morality, we found that the HR managers have only made minor adjustments to current procedures. There is a dearth of evidence that HR managers have gone beyond first order change or reorientation (Laughlin 1991).

The implications of this study are twofold. First, through analysis of the interplay of private, conventional and enacted morality, the contested terrain of green HR and what is enabling and $\infty$ nstraining the green HR agenda has been examined. We believe that any corporate shift from a 'business as usual' position to a more environmentally responsible paradigm requires company-wide environmental sensibilities; something that we are not presently seeing occurring within HR. Instead what was found can be consdered as an organisational rhetoric of weak sustainability. The business case was often used to support the presence of environmental initiatives within some participant's organizations, for example, printing policies save money. However the business case was also used as a defence by some participants for the lack of action regarding the environment, for example that they do not have the resources in HR to spend on the environment. Some felt this was particularly the case in the current economic recession in which some have barely money for core HR functions such as training, let alone the resources for the 'extras' such as supporting the environment. This position is about protecting and advancing the economy over the environment, and is to us concerning as economically driven initiatives will not go far enough in creating environmentally sustainable organisations.

Despite the absence of a 'strong' sustainability perspective, we believe that $\mathrm{HR}$, due to the core functions it undertakes, has the potential to be a vanguard in the corporate environmental movement. We would suggest however, that this leadership role is not occurring, and pose the unsettling suggestion that currently HR may in fact constitute a rearguard. Based on our findings, we argue that environmental sustainability has not largely affected the role of $\mathrm{HR}$, nor have HR managers begun to examine what sustainability means for various HR functions Of greater concern is that the HR managers interviewed could not clearly articulate what action they could take in specific HR functions. Further research is therefore needed which explores how the environmental agenda could influence HR functions. For example, with regard to training and development, HR managers could consider the following questions:

- Can our em ployees articulate the organisation's sustainable development principles?

- Do our employees understand what our mission to be carbon neutral means?

- Are our contractors evaluated for their environmental practices?

- Do we realise our workplace as a key learning site for environmental values and actions?

- Have we integrated content on the environment into our leadership development programmes?

As Fineman (1997: 37) states: "the environment belongs' to everyone, its damage is quintessentially a matter of broad-consensual moral concern and organisational actors are as culpable as anyone else". We urge HR managers to reconsider the implications of what 
their passive position on the environment could mean, given their important role for shaping people's behaviour in organisations and beyond.

\section{REFERENCES}

Bebbington, J. \& Gray, R. (2001). An account of sustainability: Failure, success and a reconceptualization. Critical Perspectives on Accounting, 12: 557-587.

Davies, G. \& Smith, H. (2007-8 March). HR goes green. People Management Magazine, 26

Dobson, A. (1999). Fairness and futurity: Essays on environmental sustainability and social justice, (pp. 21-45). New York: Oxford University Press.

Dryzek, J. S. (1997). The politics of the earth: Environmental discourses. Oxford: Oxford University Press.

Elkington, J. (1997). Cannibals with forks: The triple bottomline of $21^{\text {st }}$ century business. Oxford: Capstone.

Fineman, S.(1997). Constructing the green manager. British Journal of Management, 8: 31 38.

Glade, B. (2008). Human resources: CSR and busness sustainability - HR's leadership role. Manage ment, October: 51-52.

Gladwin, T. N., Kennelly, J. J. \& Krause, T. (1995). Shifting paradigm s for sustainable development: Implications for management theory and research. Academy of Manage ment Review, 20(4): 874-907.

Gray, R. \& Bebbington, J. (2001). Accounting for the Environment. London: Sage.

Hart, S. (1995). A natural-resource-based view of the firm. Academy of Management Review, 20(4): 986-1014.

Hawken, P. (1992). The ecology of $\infty$ mmerce: A declaration of sustainability. New York: HarperBusiness.

Jacobs, M. (1999). Sustainable development as a contested concept. In A. Dobson. (Ed.). Fairness and futurity: Essays on environmental sustainability and social justice, (pp. 21 45). New York: Oxford University Press.

Laughlin, R. (1991). Environmental disurbances and organizational transitions and transformations: Some alternative models. Organization Studies, 12(2): 209-232.

Milne, M.J., Kearins, K. \& Walton, S. (2006). Creating adventures in wonderland: The journey metaphor and environmental sustainability. Organization, 13(6): 801-839.

Milne, M.J., Tregidga, H. \& Walton, S. (2008). Words of action: The centrist and pragmatic discourse of sustainable development reporting. Paper accepted for presentation at the 2008 Acade my of Management Annual Meeting, Anaheim, California, 8-13 August.

Prasad, P. \& Elmes, M. (2005). In the name of the practical: Unearthing the hegemony of pragmatics in the discourse of environmental management. Journal of Management Studies, 42(4): 845-867.

Purser, R. E., Park, C. \& Montuori, A. (1999). Limits to anthropocentrism: Toward an ecocentric organizational paradigm? Academy of Management Review, 20: 1053-1090.

Sachs, W. (1999). Sustainable development and the crisis of nature: On the political anatomy of an oxymoron. In F. Fischer. \& M. Hajer. (Eds.). Living with nature: Environmental politics as cultural discourse. Oxford: Oxford University Press.

Shrivastava, P. (1994). CASTRATED environment: GREENING organizational studies. Organization Studies, 15(5): 705-726.

Sarkis, J. (2006). Greening the Supply Chain. New York: Greenleaf.

Starik M. \& Rands, G. (1995). Weaving an integrated web: Multilevel and multisystem perspectives of ecologically sustainable organizations. Acade my of Management Review, 20(4): 908-935.

Unerman, J., Bebbington, J. \& O'Dwyer, B. (2007). Sustainability Accounting and Accountability. London: Routledge.

Wackernagel, M. \& Rees, W. (1996). Our ecological footprint: Reducing human impact on the earth. Canada: New Society.

Welford, R. (1997). Hijacking environmentalism: Corporate responses to sustainable develop ment. London: Earthscan. 